Jurnal Riset Kesehatan

http://ejournal.poltekkes-smg.ac.id/ojs/index.php/jrk

\title{
PERBEDAAN KUALITAS CITRA ANATOMIS PEMERIKSAAN COMPUTED TOMOGRAPHY ANGIOGRAPHY (CTA) AORTA ABDOMINALIS DENGAN VARIASI NILAI THRESHOLD
}

\author{
Nisa Izzaty Khoirina*) ; Yeti Kartikasari ; Sudiyono \\ Rumah Sakit Pupuk Kalimantan Timur \\ Jl. Oxygen No. 01 Komp. PT. Pupuk Kaltim ; Kota Bontang
}

\begin{abstract}
Abstrak
Aorta abdomen CTA adalah pemeriksaan radiologis minimal invasif dengan media kontras yang masuk melalui pembuluh darah, yang bertujuan menghasilkan radiografi aorta abdomen dengan menggunakan modalitas CT-Scan. Nilai threshold terkait erat dengan perubahan waktu tunda pemindaian yang akan mempengaruhi penambahan vaskular, dan dapat berdampak pada resolusi kontras sehingga akan mempengaruhi kualitas gambar. Penelitian ini dilakukan dengan menggunakan CT-Scan 64 slice untuk menilai perbedaan kualitas gambar pada pemeriksaan abdomen CTA Aorta dengan variasi threshold 100 HU, 150 HU dan 200 HU. Uji statistic Kruskal Wall is diikuti oleh uji statistik post hoc Mann Whitney yang digunakan untuk melihat perbedaan variasi threshold. Hasil penelitian menunjukkan perbedaan yang signifikan pada pemeriksaan abdomen CTA Aorta dengan nilai $\mathrm{p}<0.00$ ( $\mathrm{p}<0,05)$. Variasi optimal yang digunakan dalam pemeriksaan pemeriksaan abdomen CTA Aorta adalah pada nilai threshold $150 \mathrm{HU} .150 \mathrm{HU}$ adalah threshold optimal untuk pemeriksaan CTA aorta abdomen dengan variasi nilai threshold antara 100 HU, $150 \mathrm{HU}$ dan $200 \mathrm{HU}$, namun untuk patologi arteri ginjal sebaiknya menggunakan nilai threshold $100 \mathrm{HU}$ dan $200 \mathrm{HU}$ untuk kelainan pada arteri hepatik.
\end{abstract}

Kata kunci: CTA; Abdomen; Threshold; Aorta

\begin{abstract}
[ANATOMIC IMAGE QUALITY DIFFERENCE OF COMPUTED TOMOGRAPHY ANGIOGRAPHY (CTA) ABDOMINAL AORTA WITH VARIATION OF THRESHOLD VALUE] Abdominal aorta CTA is minimally invasive radiological examinations with contrast medium entering through the blood vessels, aiming to produce a radiograph of the abdominal aorta using CT scan modality. The threshold value is closely related to changes time scan delay that will affect the vascular enhancement, and can have an impact on the contrast resolution so it will affect the image quality. This research performed by using the 64 slices of CT-Scan modality to assess differences in the quality of the image on the CTA Aorta abdominal examination with variations of threshold $100 \mathrm{HU}, 150 \mathrm{HU}$ and $200 \mathrm{HU}$. Kruskal Wallis followed by Mann Whitney post hoc statistical test used to look at differences in threshold variation. The result showed significant differences in CTA Aorta abdominal examination with a $\mathrm{p}$ value of $<0.00(\mathrm{p}<0.05)$. Optimal variation used in the examination of CTA Aorta abdominal examination is in threshold value $150 \mathrm{HU}$. $150 \mathrm{HU}$ was optimal threshold for the CTA examination of the abdominal aorta with a variation of the threshold value between $100 \mathrm{HU}, 150 \mathrm{HU}$ and $200 \mathrm{HU}$, however for the pathology of renal artery preferably using threshold value of $100 \mathrm{HU}$ and $200 \mathrm{HU}$ for hepatic artery pathologic.
\end{abstract}

Keywords: CTA ; Abdomen; threshold ; aorta

*) Penulis Korespondensi.

E-mail: nszztykhrn@gmail.com 


\section{Pendahuluan}

Perkembangan teknologi pencitraan dalam bidang diagnostik sangat pesat, salah satu inovasi teknologi pencitraan yang terus berkembang adalah Computed Tomography Scan (CT Scan). CT Scan merupakan salah satu sarana penunjang penegakan diagnosa yang menggunakan gabungan dari sinar- $X$ dan komputer untuk mendapatkan citra atau ga mbar berupa variasi irisan tubuh manusia (Bontrager, 2010). Seiring dengan perkembangan teknologi, dewasa ini telah diciptakan alat CT Scan yang lebih canggih yaitu Multi Slice Computed Tomography (MSCT). Prinsip MSCT adalah pergerakan tabung sinar- $X$ yang berputar secara stasioner dan memancarkan sinar- $X$ secara kontinyu, sambil diiringi pergerakan pasien oleh control table, melewati bidang penyinaran sehingga akan dihasilkan banyak potongan (multi slice) dalam satu kali pergerakan pasien (Said, 2008). MSCT dengan berbagai keunggulan diantaranya kecepatan scan yang tinggi, karakter resolusi tinggi, akuisisi volume memberikan gambaran detail sehingga tepat digunakan untuk pemeriksaan Computed Tomography Scan Angiography (CTA).

CTA adalah pemeriksaan radiologi invasif minimal dengan memasukan media kontras melalui pembuluh darah, dengan tujuan untuk melihat pembuluh darah pada tubuh dengan menggunakan modalitas CT scan. CTA telah berhasil digunakan untuk mendeteksi kelainan dan anatomi pembuluh darah, masalah dan penyakit tertentu. CTA berguna menggambarkan sistem saraf, aorta abdomen dan aorta thorax (Fishmann dan Jeffrey,1998).

Menurut Corey Goldman dan Javier Sanz (2005), CTA aorta abdominal dapat memvisualisasi aorta abdominalis dan organ visceral untuk vaskular anatomi dan mendiagnosa kelainan yang mempengaruhi sistem vaskular diantaranya acute aortic syndrome, abdominal aneurysm, renal artery stenosis, mesenteric ischemia dan tumor. Karena itu digunakan untuk perencanaan terapi endovaskuler, pengobatan onkologi, bedah transplantasi dan trauma multi sistem.

Menurut Corey (2006), prosedur pemeriksaan CTA aorta abdominal dilakukan dengan persiapan pasien dengan puasa selama minimal empat jam sebelum pemeriksaan. Scanning dimulai dari costae 12 hingga caput femoralis atau crista iliaca, scaning dimulai dengan posisi head first dengan pemberian kontras media. Pemeriksaan dilakukan dengan slice thickness $10 \mathrm{~mm}$. Kontras media yang digunakan pada pemeriksaan CTA aorta abdominal adalah kontras media non-ionik (konsentrasi iodium $300-400 \mathrm{mgI} / \mathrm{ml}$ ) sebanyak $100 \mathrm{ml}$ dengan contrast injection rate (rata-rata injeksi) 3-4 ml per detik menggunakan bolus tracking dengan meletakkan region-of-interest (ROI) di atas truncus coeliacus hingga nilai threshold mencapai 150-200 HU.

Pada pemeriksaan CTA aorta abdominal, penentuan waktu scanning yang tepat adalah hal penting untuk menghasilkan radiograf yang baik. Penentuan waktu scaning diperoleh dari time scan delay dengan pengaplikasian nilai threshold pada metode bolus tracking. Nilai threshold adalah nilai yang didapat saat enhancement media kontras pada titik ROI mencapai nilai HU tertentu dan enhancement adalah penyangatan suatu organ atau jaringan yang diukur dengan nilai HU dari kritikal anatomi yang ditetapkan dengan ROI (Bae, 2006).

Menurut Bontrager (2001), kualitas citra meliputi semua faktor yang berhubungan dengan akurasi dengan menampakkan struktur dan jaringan ke dalam radiograf atau citra. Berdasarkan pengertian tersebut, maka kualitas citra CTA aorta abdominalis yang baik harus dapat menampakkan bagian-bagian pembuluh darah aorta abdominalis yang diduga mengalami kelainan. Beberapa faktor yang mempengaruhi kualitas citra yaitu artefak, spasial resolusi, noise dan kontras resolusi. Menurut Seeram (2001) dan Bushberg, (2003) kontras resolusi adalah kemampuan untuk membedakan atau menampakkan obyek-obyek dengan perbedaan densitas yang sangat kecil.

Perubahan nilai threshold erat kaitannya dengan perubahan time scan delay yang akan berpengaruh pada enhacement vaskular, dan enhancement vaskular dapat berdampak pada kontras resolusi dan akan mempengaruhi kualitas citra radiograf. Faktor-faktor di atas saling berkaitan sehingga dapat mempengaruhi interpretasi radiolog dalam membaca radiograf.

\section{Metode}

Penelitian ini merupakan penelitian pre-experimental design with control dengan metode one-shoot case study. Pemeriksaan CTA dilakukan dengan menggunakan modalitas CT-Scan 64 slice untuk menilai perbedaan kualitas citra pada pemeriksaan CTA Aorta 
Abdominalis dengan variasi nilai threshold 100 HU, 150 HU dan 200 HU. Populasi dari penelitian ini adalah semua pasien yang melakukan pemeriksaan CTA Aorta Abdominalis di RSU dr. Kanujoso Djatiwibowo Balikpapan. Besar sampel yang seharusnya digunakan pada penelitian variasi nilai threshold $100 \mathrm{HU}, 150 \mathrm{HU}$ dan $200 \mathrm{HU}$ pada pemeriksaan CTA Aorta Abdominal ini menurut hitungan rumus Federer adalah 9 orang sampel atau lebih pada tiap variasi nilai threshold. Dengan demikian jumlah semua sampel seharusnya adalah 27 orang atau lebih. Namun, terdapat keterbatasan dalam penelitian ini dikarenakan waktu penelitian yang sempit sehingga peneliti hanya mendapatkan 9 orang sampel dengan 3 sampel pada setiap variasi nilai threshold.

Dapat disimpulkan bahwa data yang diperoleh tidak berdistribusi normal, karena tidak memenuhi jumlah sampel minimal pada rumus frederer, sehingga digunakan uji statistik Kruskal-Walis untuk melihat melihat perbedaan yang bermakna pada kualitas citra anatomis pemeriksaan CTA Aorta Abdominalis dengan variasi nilai threshold, serta melihat mean rank tertinggi yang berarti nilai threshold tersebut merupakan nilai threshold yang optimal untuk pemeriksaan CTA Aorta Abdominalis, dilanjutkan dengan uji Post Hoc Mann Whitney untuk melihat perbedaan yang bermakna pada kualitas citra dengan membandingkan tiap variasi nilai threshold.

\section{Hasil dan Pembahasan}

\section{Deskripsi Sampel}

Sampel penelitian ini merupakan hasil reformat CTA Aorta Abdominalis dengan menggunakan pesawat Siemens 64 Slice di Instalasi Radiologi Rumah Sakit dr. Kanujoso Djatiwibowo Balikpapan. Objek penelitian adalah 9 orang sample degan variasi nilai threshold yang berbeda-beda, yaitu 3 orang dengan nilai threshold $100 \mathrm{HU}, 3$ orang dengan nilai threshold $150 \mathrm{HU}$ dan 3 orang dengan nilai threshold 200 HU. Pasien dipilih berdasarkan kriteria yang telah di tentukan yaitu berat badan antara 50-70 kg, usia antara 35-55 th dan tinggi badan antara 150-170 $\mathrm{cm}$ dengan tekanan darah sistole 100-120 mmHg. Kriteria tersebut menurut Bae (2006) adalah faktor-faktor yang dapat mempengaruhi peningkatan contrast enhancement termasuk time scan delay, volume media kontras, kecepatan injeksi dan larutan saline agar variabel bebas yaitu nilai threshold dapat di kontrol.

Hasil Scaning ketiga variasi nilai threshold kemudian diolah ke dalam image maximum intensity projection (MIP) dengan mula-mula mengatur rekonstruksi increment sebesar $0.3 \mathrm{~mm}$, kurang-lebih setengah dari pemilihan slice thickness setebal $0.625 \mathrm{~mm}$. Kemudian mengatur rekontruksi kernel very smooth angio. Setelah itu hasil image yang telah direkonstruksi dikirim ke reformat tiga dimensi. Setelah didapatkan hasil rekonstruksi, kemudian dilakukan pengolahan gamber menggunakan aplikasi bone removal untuk menghilangkan tulang-tulang disekitar abdomen sehingga didapatkan gambaran jaringan lunak. Langkah selanjutnya yaitu melakukan rekonstruksi gambar MIP sehingga didapatkan gambaran pembuluh darah yang akan dinilai oleh radiolog. Berikut adalah gambaran MIP Aorta Abdominalis yang di nilai oleh radiolog.

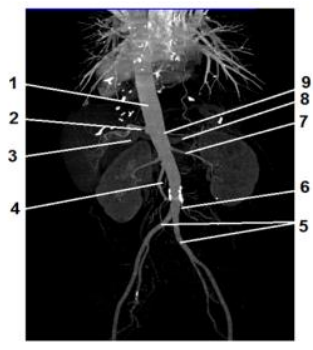

\section{Keterangan}

Aorta Abdominal

Arteri Lienalis

Arteri Hepatika

Arteri mesentrika superior

Arteri iliaka komunis

Arteri mesentrika inferior

Arteri Renalis

Arteri Splenika

Arteri Gastrika

\section{Deskripsi Hasil Pemeriksaan}

Sembilan lembar hasil reformat gambaran MIP masing-masing pasien kemudian dinilai oleh tiga responden radiolog untuk mendapatkan nilai kualitas dan perbedaan hasil gambaran MIP pemeriksaan CTA Aorta Abdominalis dengan variasi nilai threshold dengan menggunakan instrument berupa lembar kuesioner. Kuesioner tersebut berisi tabel dengan delapan kriteria anatomi yang dinilai, tabel tersebut berupa isian tentang bagaimana gambaran arteri splenika, arteri gastrika, arteri hepatika, arteri lienalis, arteri mesenterika superior dan inferior, arteri renalis serta arteri iliaka komunis yang dihasilkan dan kejelasan anatomi tersebut. Rentang nilainya adalah 1 sampai 3; nilai 1 merupakan nilai minimal dan nilai 3 merupakan nilai maksimal. Jadi setiap radiograf akan mempunyai nilai 24 sebagai nilai tertinggi dan 8 sebagai nilai terendah.

Setelah semua responden mengisi kuesioner yang ada, penilaian responden kemudian direkapitulasi untuk mengetahui nilai yang diperoleh dari masing-masing hasil gambaran MIP Aorta abdominalis. Rekapitulasi 
tersebut adalah keseluruhan penilaian dari 3 responden, kemudian nilai tersebut dijumlahkan dari masing-masing responden.

Tabel 1. Hasil Penilaian 3 Orang Responden

\begin{tabular}{|c|c|c|c|c|c|c|c|c|c|}
\hline \multirow{2}{*}{$\begin{array}{c}\text { Citra yang } \\
\text { dinilai }\end{array}$} & \multicolumn{3}{|c|}{ Pasien 1} & \multicolumn{3}{|c|}{ Pasien 2} & \multicolumn{3}{|c|}{ Pasien 3} \\
\hline & $\mathrm{R} 1$ & $\mathrm{R} 2$ & $\mathrm{R} 3$ & $\mathrm{R} 1$ & $\mathrm{R} 2$ & R3 & $\mathrm{R} 1$ & $\mathrm{R} 2$ & $\mathrm{R} 3$ \\
\hline Arteri Spleenika & 2 & 1 & 2 & 1 & 1 & 2 & 2 & 1 & \\
\hline Arteri Gastrika & 2 & 2 & 2 & 1 & 2 & 1 & 2 & 2 & \\
\hline Arteri Hepatika & 1 & 2 & 2 & 2 & 2 & 2 & 2 & 1 & \\
\hline Arteri Lienalis & 2 & 1 & 2 & 2 & 2 & 2 & 2 & 2 & 2 \\
\hline $\begin{array}{l}\text { Aretri } \\
\text { mesenterika } \\
\text { superior } \\
\text { Arteri }\end{array}$ & 2 & 1 & 2 & 2 & 2 & 2 & 2 & 2 & 2 \\
\hline $\begin{array}{l}\text { mesenterika } \\
\text { inferior }\end{array}$ & 2 & 1 & 1 & 1 & 1 & 2 & 1 & 1 & 1 \\
\hline Arteri renalis & 2 & 2 & 2 & 2 & 2 & 2 & 2 & 2 & 2 \\
\hline $\begin{array}{l}\text { Arteri iliaka } \\
\text { komunis }\end{array}$ & 2 & 2 & 1 & 2 & 2 & 2 & 1 & 2 & 2 \\
\hline Jumlah & 15 & 12 & 14 & 13 & 14 & 15 & 14 & 13 & 14 \\
\hline Rata-rata pasien & & 15 & & & 14 & & & 13.67 & \\
\hline
\end{tabular}

Tabel 2. Hasil Penilaian 3 Orang Responden pada Nilai Threshold $150 \mathrm{HU}$

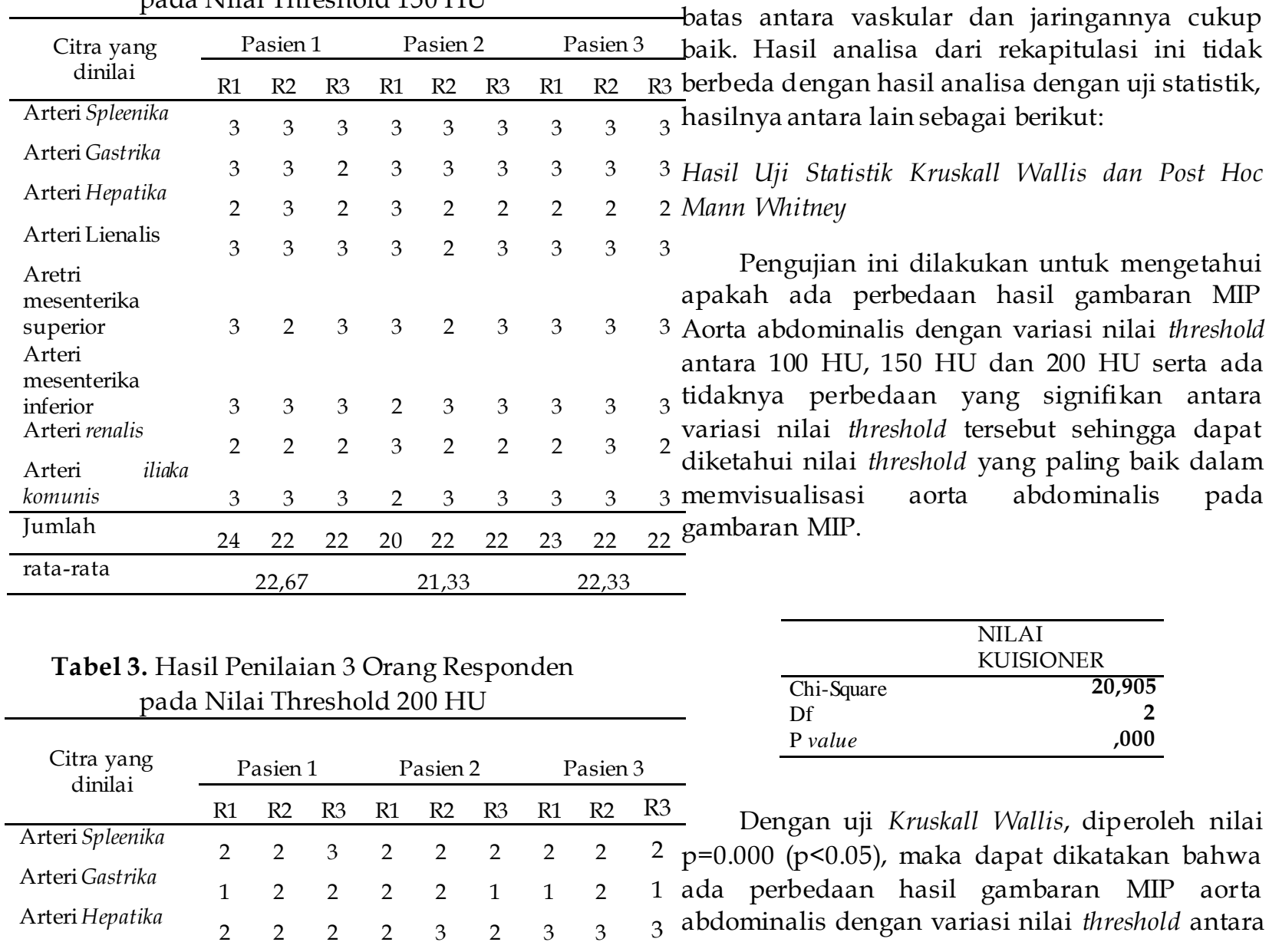

$\begin{array}{llllllllll}\text { Arteri Lienalis } & 3 & 3 & 2 & 2 & 2 & 3 & 2 & 2 & 2\end{array}$

Aretri

mesenterika superior

Arteri

mesenterika inferior Arteri renalis

$\begin{array}{lllllllll}2 & 1 & 2 & 1 & 2 & 1 & 1 & 2 & 1\end{array}$

komunis

ilika

\begin{tabular}{lccccccccc}
\hline Jumlah & 15 & 17 & 15 & 15 & 16 & 14 & 15 & 17 & 14 \\
\hline rata-rata & 15,67 & & & 15 & & & 15,33 & \\
\hline
\end{tabular}

Berdasarkan data tersebut dapat disimpulkan bahwa nilai threshold yang diberikan nilai tertinggi oleh responden adalah nilai threshold $150 \mathrm{HU}$. Responden berpendapat bahwa hasil gambar MIP aorta abdominalis dengan nilai threshold $150 \mathrm{HU}$ adalah radiograf 2 dengan batas antara vaskular dan jaringan sangat jelas serta penyangatan vaskuler sangat baik.

Pada hasil gambar MIP aorta abdominalis dengan nilai threshold $100 \mathrm{HU}$ adalah nilai terendah yang di berikan oleh responden, sedangkan pada MIP aorta abdominalis dengan nilai threshold $200 \mathrm{HU}$ merupakan radiograf yang batas antara vaskular dan jaringannya cukup berbeda dengan hasil analisa dengan uji statistik,

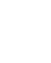


tiga kelompok. Dengan demikian dapat diartikan bahwa Ho ditolak dan Ha diterima.

Untuk mengetahui urutan nilai rata-rata dari hasil gambaran MIP aorta abdominalis dari masing-masing variasi nilai threshold, dilakukan Kruskall Wallis mean rank, mean rank tertinggi adalah variasi nilai threshold 150 HU berdasarkan tabel berikut:

\begin{tabular}{llll}
\hline & Variasi nilai threshold & N & Mean Rank \\
\hline Nilai Kuisioner & $100 \mathrm{HU}$ & $\mathbf{9}$ & $\mathbf{6 , 3 3}$ \\
& & $\mathbf{9}$ & $\mathbf{2 3 , 0 0}$ \\
& $150 \mathrm{HU}$ & $\mathbf{9}$ & $\mathbf{1 2 , 6 7}$ \\
& $200 \mathrm{HU}$ & $\mathbf{2 7}$ & \\
\hline & Total & &
\end{tabular}

Selanjutnya untuk mengetahui adanya perbedaan bermakna atau tidak pada perbandingan tiap-tiap variasi nilai threshold satu sama lain, maka dilakukan analisis Post Hoc Mann Whitney. Langkahnya adalah melakukan perbandingan ketiga variasi nilai threshold dengan membandingkan dua variasi satu sama lain, yaitu antara penggunaan nilai threshold 100 HU den gan $150 \mathrm{HU}, 100 \mathrm{HU}$ dengan $200 \mathrm{HU}$ dan $150 \mathrm{HU}$ dengan $200 \mathrm{HU}$. Hasilnya adalah sebagai berikut :

\begin{tabular}{cccc}
\hline \multirow{2}{*}{ Mann } & \multicolumn{3}{c}{ Variasi nilai threshold } \\
\cline { 2 - 4 } Whitney & 100 & 100 & 150 \\
Test & $\mathrm{HU}$ & $\mathrm{HU}$ & $\mathrm{HU}$ \\
& deng & dengan & dengan \\
& $\mathrm{an}$ & 200 & 200 \\
& 150 & $\mathrm{HU}$ & $\mathrm{HU}$ \\
& $\mathrm{HU}$ & & \\
\hline p value & $\mathrm{p}=0.0$ & $\mathrm{p}=0.02$ & $\mathrm{p}=0.00$ \\
& 00 & 0 & 0 \\
\hline
\end{tabular}

Dengan demikian dari tabel tersebut dapat disimpulkan bahwa terdapat perbedaan yang bermakna antara hasil gambaran MIP aorta abdominalis pada semua variasi nilai threshold karena semua $\mathrm{p}$ value dari setiap perbandingan nilai threshold lebih kecil dari 0.05 .

\section{Pembahasan}

Dari hasil penjabaran di atas, baik secara manual berdasarkan hasil rekapitulasi maupun menggunakan uji statistik dapat diketahui bahwa terdapat perbedaan pada kualitas citra anatomis gambaran MIP aorta abdominalis dengan variasi nilai threshold.

Berdasarkan hasil uji statistik Post Hoc Mann-Whitney terhadap hasil gambaran MIP aorta abdominalis pada semua variasi nilai threshold (tabel 11) diperoleh $\mathrm{p}$ value $<0.05$ maka Ho ditolak dan Ha diterima, artinya ada perbedaan kualitas citra anatomis dengan variasi nilai threshold pada pemeriksaan CTA aorta abdominalis.

Sedangkan untuk menentukan mean rank tertinggi, di lakukan uji statistik Kruskal Wallis (tabel 10) dan diperoleh hasil 150 HU merupakan nilai threshold dengan nilai mean rank tertinggi. Hal ini merupakan suatu tanda bahwa $150 \mathrm{HU}$ merupakan nilai threshold yang optimal.

Perbedaan penggunaan nilai threshold pada pemeriksaan CTA Aorta Abdominalis

Kualitas citra radiograf CTA Aorta Abdominalis sebagai output dari pada penelitian ini sangat dipengaruhi oleh beberapa faktor yaitu artefak, spasial resolusi, noise dan kontras resolusi (Bontranger, 2001). Kontras resolusi erat kaitannya dengan enhancement vaskular dari radiograf Aorta Abdominalis yang akan dinilai oleh responden pada penelitian ini.

Pada pemeriksaan CTA Aorta Abdominal, penentuan waktu scaning yang tepat adalah hal yang sangat penting untuk menghasilkan radiograf yang baik. Penentuan waktu scaning diperoleh dari time scan delay dengan pengaplikasian nilai threshold sehingga scanning di mulai ketika gambaran kurva meningkat mencapai peak enhancement. Oleh karena itu pengunaan nilai threshold akan banyak mempengaruhi enhancement vaskular pada radiograf.

Setelah dilakukan penelitian penggunaan nilai threshold dengan variasi $100 \mathrm{HU}, 150 \mathrm{HU}$ dan 200 HU pada pemeriksaan CTA Aorta Abdominal kemudian hasil citra CTA tersebut di berikan penilaian oleh tiga orang radiolog, diperoleh bahwa penilaian radiolog terhadap enhancement vaskular memiliki perubahan disetiap variasi nilai threshold yang digunakan dalam penelitian ini.

Berdasarkan hasil pengujian statistik, pada uji beda yang dilakukan dengan uji Kruskal Wallis yang kemudian dilanjutkan dengan uji Post-hoc Mann Whitney, didapat kesimpulan bahwa ada perbedaan yang bermakna pada perbedaan kualitas citra pemeriksaan CTA Aorta Abdominalis dengan variasi nilai threshold.

Perbedaan tersebut dapat dilhat pada tabel tabulasi hasil penilaian responden (tabel 6, 7 dan 8). Pada nilai threshold $100 \mathrm{HU}$ rata-rata penilaian yang diberikan responden terhadap arteri splenika, arteri gastrika, arteri hepatika, arteri 
lienalis, arteri mesenterika superior dan inferior, arteri renalis serta arteri iliaka komunis adalah cukup baik dengan penilaian yang terbaik pada nilai threshold $100 \mathrm{HU}$ adalah arteri renalis dan tidak enhance adalah arteri mesenterika inferior. Namun, gambaran arteri renalis pada nilai threshold 100 HU tidak lebih baik bila dibandingkan dengan penilaian arteri renalis pada nilai threshold $150 \mathrm{HU}$ dan $200 \mathrm{HU}$.

Pada nilai threshold 150 HU merupakan nilai yang paling tinggi dibandingkan dengan nilai threshold yang lain, rata rata penilaian responden terhadap setiap organ adalah sangat baik dengan organ yang paling jelas adalah arteri spleenika dan yang kurang jelas adalah arteri renalis.

Pada nilai threshold $200 \mathrm{HU}$, penilaian rata rata responden perorgan cukup baik, organ yang paling enhance yang dinilai radiolog adalah arteri hepatika sedangkan yang tidak enhance adalah arteri mesenterika inferior. Arteri hepatika pada nilai threshold $200 \mathrm{HU}$ lebih baik nilainya daripada gambaran arteri hepatika pada nilai threshold $100 \mathrm{HU}$ dan $150 \mathrm{HU}$, sehingga apabila dicurigai terdapat patologis atau kelainan di daerah arteri hepatika, sebaiknya menggunakan nilai threshold $200 \mathrm{HU}$.

Dari gambaran di atas dapat disimpulkan bahwa nilai threshold yang batas antara vaskular dengan jaringan sangat jelas dan penyangatan vaskuler sangat baik adalah $150 \mathrm{HU}$, namun berdasarkan penilaian radiolog (tabel 5,6 dan 7) apabila terdapat patologi pada arteri hepatika sebaiknya menggunakan nilai threshold $200 \mathrm{HU}$.

Nilai threshold yang paling optimal pada pemeriksaan CTA Aorta Abdominalis

Pada tabel tabulasi hasil penilaian responden (tabel 6, 7 dan 8) dan tabel hasil uji Kruskall Wallis (tabel 9 dan 10), nilai threshold $150 \mathrm{HU}$ merupakan nilai threshold dengan mean rank tertinggi. Menunjukan bahwa nilat threshold tersebut adalah yang paling baik dalam memvisualisasi aorta abdominalis pada gambaran MIP.

Nilai threshold yang menjadi variabel bebas pada penelitian ini berhubungan erat dengan time scan delay, semakin tinggi nilai threshold yang di gunakan maka akan semakin lama pula waktu yang dibutuhkan untuk mencapai puncak kurva peak enhancement. Sebagai contoh pada penggunaan nilai threshold $100 \mathrm{HU}$, waktu yang dibutuhkan untuk mencapai puncak kurva peak enhancement adalah 15 detik. Pada penggunaan nilai threshold $150 \mathrm{HU}$, waktu yang dibutuhkan untuk mencapai puncak kurva peak enhancement adalah 20 detik. Sedangkan pada penggunaan nilai threshold $200 \mathrm{HU}$, waktu yang dibutuhkan untuk mencapai puncak kurva peak enhancement adalah 25 detik.

Media kontras yang masuk melalui pembuluh vena pada flow rate $3,5 \mathrm{ml} /$ detik dengan volume $100 \mathrm{ml}$ (media kontras $80 \mathrm{ml}$ dan larutan $\mathrm{NaCl} 20 \mathrm{ml}$ ) akan habis seluruhnya dalam waktu 28,5 detik. Untuk mendapatkan enhancement vaskular yang optimal diharapkan scanning dimulai saat media kontras sedang melewati pembuluh darah. Delay scan setelah peak enhancement pada semua perlakuan sampel telah diatur sama yaitu 4 detik. Sehingga waktu scanning pada penggunaan nilai threshold $100 \mathrm{HU}$ dimulai pada detik ke 19, pada nilai threshold 150 HU dimulai pada detik ke 24 dan pada nilai threshold $200 \mathrm{HU}$ dimulai pada detik ke 29.

Hal ini lah yang menyebabkan pada penggunaan nilai threshold $100 \mathrm{HU}$, media kontras belum mengisi penuh arteri-arteri di sekitar aorta abdominalis sehingga batas antara vaskular dengan jaringan tidak baik dan penyangatan vaskuler dinilai kurang terang. Sedangkan pada penggunaan nilai threshold 200 HU media kontras telah melewati arteri-arteri di sekitar aorta abdominalis dan sebagian sudah mulai memasuki pembuluh darah vena sehingga enhancement vaskuler kurang terang dibandingkan dengan penggunaan nilai threshold $150 \mathrm{HU}$.

Pada penggunaan nilai threshold $150 \mathrm{HU}$, scaning dimulai saat pertengahan media kontras melewati pembuluh darah, media kontras telah memasuki arteri-arteri disekitar aorta abdominalis namun belum masuk kedalam pembuluh vena sehingga enhancement vaskular sedang berada pada kondisi maksimal.

Menurut Bae (2006), hal-hal yang dapat mempengaruhi enhancement adalah flow rate, konsentrasi iodium, volume media kontras, saline flush dan time scan delay. Flow rate berpengaruh terhadap magnitude enhancement, semakin tinggi flow rate yang digunakan maka semakin panjang magnitude enhancement. Flow rate yang tinggi membutuhkan time scan delay lebih pendek agar scanning tepat saat peak enhancement. Flow rate yang digunakan pada penelitian ini adalah $3.5 \mathrm{ml} / \mathrm{s}$, dengan nilai threshold $150 \mathrm{HU}$ yang merupakan nilai threshold yang paling optimal dalam pencitraan aorta abdominalis delay time yang digunakan adalah 4 detik. 
Pada penggunaan nilai threshold $100 \mathrm{HU}$ jika menginginkan hasil radiograf dengan enhancement yang sama dengan penggunaan nilai threshold 150 HU maka flow rate yang digunakan harus lebih lambat dari $3,5 \mathrm{ml} / \mathrm{s}$ dengan delay time yang sama yaitu 4 detik. Sedangkan pada penggunaan nilai threshold 200 HU jika menginginkan hasil radiograf dengan enhancement yang sama dengan penggunaan nilai threshold $150 \mathrm{HU}$, maka yang harus dilakukan adalah mempercepat laju flow rate diatas 3,5 ml/s, namun hal ini harus di sesuaikan dengan penggunaan jarum abocath, semakin cepat flow rate jarum abocath harus semakin besar.

Konsentrasi iodium juga berpengaruh terhadap magnitude enhancement, semakin besar kandungan iodium pada media kontras maka magnitude enhancement akan semakin besar. Volume media kontras yang masuk kedalam tubuh pasien dapat dipilih melalui dua cara yaitu menggunakan konsentrasi tinggi dengan volum yang sedikit atau menggunakan konsentrasi rendah dengan volume media kontras yang banyak. Media kontras yang dipilih untuk digunakan adalah $370 \mathrm{mgI} / \mathrm{ml}$ sebanyak $80 \mathrm{ml}$.

Penggunaan larutan saline bertujuan untuk mengoptimalkan enhancement dengan mendorong sisa kontras yang ada pada selang infus, saline juga berfungsi untuk memperpanjang waktu magnitude enhancement. Pada penelitian ini penggunaannya $20 \mathrm{ml}$ post injeksi media kontras.

\section{Simpulan dan Saran}

Dari hasil penelitian untuk mengetahui perbedaan kualitas citra anatomis pemeriksaan CTA Aorta Abdominalis dengan variasi nilai threshold diketahui bahwa ada perbedaan yang signifikan terhadap variasi nilai threshold yang digunakan dalam pemeriksaan CTA Aorta Abdominalis. Hal ini terlihat dari $\mathrm{p}$ value 0.000 ( $\mathrm{p}<0.05)$ dari uji statistik yang telah lakukan. nilai threshold yang optimal untuk pemerisaan CTA aorta abdominalis $150 \mathrm{HU}$ adalah dari variasi nilai threshold antara $100 \mathrm{HU}, 150 \mathrm{HU}$ dan $200 \mathrm{HU}$, namun untuk patologi pada arteri hepatika menggunakan nilai threshold $200 \mathrm{HU}$.

\section{Ucapan Terima Kasih}

Terima kasih disampaikan kepada Poltekkes Kemenkes Semarang yang telah mendanai keberlangsungan jurnal ini. Atau ucapan terima kasih terutama ditujukan kepada pemberi dana penelitian atau donatur. Ucapan terima kasih dapat juga disampaikan kepada pihak-pihak yang membantu pelaksanaan penelitian.

\section{Daftar Pustaka}

Bae T. Kyongtae. 2006. Principles of Contrast Medium delivery and scan Timing in MDCT. MDTCA Pratical Approach-Springer.

Ballinger, P.W. 1999. Radiographic Positions $\mathcal{E}$ Radiologic Procedures, tenth edition, The CV Mosby, St. Louis Missouri

Bontrager Kenneth L. 2001. Textbook of radiographic positioning and related anatomy, Missourry USA: Mosby, Inc

Boas F. Edward and Fleischmann D. 2012. CT Artifact: Cause and reduction Technique, Departement of Radiology, Stanford University, U.S.A.

Bushberg, J.T. 2003. The Essential Phisics of Medical Second Edition, Lippicot Williams and Wilkins, Philadelphia.

Corey Goldman and Javier Sanz. 2005. CT angiography of the abdominal aorta and its branches with protocols, Informa healthcare, Chennai

Fishman, E. K and Jeffrey, R. B. 1998. Spiral CT:Principles, Technique and Application. Lippincott Williams, Haggerstown, Maryland, U.S.A.

Fleischmann Dominik. 2006. CT Angiographyof Peripheral Arterial Disease, Departement of Radiology, Stanford University, U.S.A.

Gibson, John. 2002. Fisiologi dan Anatomi Modern Untuk Perawat. Jakarta: EGC.

Galanski and Prokop. 2003. Principles and Techniques of Images Reconstruction With CT, WB Saunders Company

Hoffer Mathias. 2005. CT Teaching manual: a systematic approach to CT Reading, Edition 5, Thieme Book Company USA.

Katzberg W Richard. 1992. The Contrast Media Manual, William \& Wilkins,Philadelphia

Lipson A Scott. 2006. MDCT and 3D workstations, springer Science+Busines Media Inc.

Nesseth. 2000. Procedures and Documentation for CT and MRI, Kansas: Mc Graw Hill Medical Publishing Division 
Pearce, E.C. 2011. Anatomi dan fisiologi untuk paramedic. PT Gramedia Pustaka Utama: Jakarta.

Seeram E. 2001, Computed Tomography: physical principles, clinical applications, and quality control, Philadelphia: Second edition, WB Saunders Company.

Snell Richard S. 2011. Anatomi Klinis. Edisi 6, ECG: Jakarta

Tortorici, M.R and Patrick, J.A. 1995. Advanced Radiographic and Angiographic Procedures with an Introduction to Specialized Imaging. FA. Davis Company : Philadelphia 